\title{
Nipping Cue Reactivity in the Bud: Baclofen Prevents Limbic Activation Elicited by Subliminal Drug Cues
}

\author{
Kimberly A. Young, ${ }^{1}$ Teresa R. Franklin, ${ }^{1}$ David C.S. Roberts, ${ }^{2}$ Kanchana Jagannathan, ${ }^{1}$ Jesse J. Suh, $, 1,3$ \\ Reagan R. Wetherill, ${ }^{1}$ Ze Wang, ${ }^{1}$ Kyle M. Kampman, ${ }^{1}$ Charles P. 0'Brien, ${ }^{1,3}$ and Anna Rose Childress ${ }^{1,3}$ \\ ${ }^{1}$ Department of Psychiatry, Perelman School of Medicine, University of Pennsylvania, Philadelphia, Pennsylvania $19104,{ }^{2}$ Department of Physiology and \\ Pharmacology, School of Medicine, Wake Forest University, Winston-Salem, North Carolina 27157, and ${ }^{3}$ Philadelphia VA Medical Center, Philadelphia, \\ Pennsylvania 19104
}

Relapse is a widely recognized and difficult to treat feature of the addictions. Substantial evidence implicates cue-triggered activation of the mesolimbic dopamine system as an important contributing factor. Even drug cues presented outside of conscious awareness (i.e., subliminally) produce robust activation within this circuitry, indicating the sensitivity and vulnerability of the brain to potentially problematic reward signals. Because pharmacological agents that prevent these early cue-induced responses could play an important role in relapse prevention, we examined whether baclofen-a $\mathrm{GABA}_{\mathrm{B}}$ receptor agonist that reduces mesolimbic dopamine release and conditioned drug responses in laboratory animals - could inhibit mesolimbic activation elicited by subliminal cocaine cues in cocainedependent individuals. Twenty cocaine-dependent participants were randomized to receive baclofen (60 mg/d; $20 \mathrm{mg}$ t.i.d.) or placebo. Event-related BOLD fMRI and a backward-masking paradigm were used to examine the effects of baclofen on subliminal cocaine (vs neutral) cues. Sexual and aversive cues were included to examine specificity. We observed that baclofen-treated participants displayed significantly less activation in response to subliminal cocaine (vs neutral) cues, but not sexual or aversive (vs neutral) cues, than placebo-treated participants in a large interconnected bilateral cluster spanning the ventral striatum, ventral pallidum, amygdala, midbrain, and orbitofrontal cortex (voxel threshold $p<0.005$; cluster corrected at $p<0.05$ ). These results suggest that baclofen may inhibit the earliest type of drug cue-induced motivational processing — that which occurs outside of awareness - before it evolves into a less manageable state.

Key words: addiction; baclofen; cocaine; cues; fMRI; subliminal

\section{Introduction}

Drugs of abuse and conditioned drug cues (e.g., stimuli repeatedly associated with prior drug use/delivery) reliably elicit neural activation (see meta-analyses; Chase et al., 2011; Kühn and Gallinat, 2011) and dopamine (DA) release (Volkow et al., 2006; Wong et al., 2006; Boileau et al., 2007; Fotros et al., 2013) in dorsal striatal and mesolimbic brain regions, including the ventral striatum (VS) and amygdala (AMY). In laboratory animals, these cue-induced neurochemical responses and their downstream effects (e.g., DA receptor activation) are required for the robust and persistent drug-seeking and drug-taking behaviors

\footnotetext{
Received Nov. 27, 2013; revised Feb. 27, 2014; accepted March 6, 2014.

Author contributions: A.R.C. designed research; K.M.K. and A.R.C. performed research; K.A.Y., K.J., Z.W., and A.R.C. analyzed data; K.A.Y., T.F., D.C.S.R., J.J.S., R.R.W., C.P.O., and A.R.C. wrote the paper.

The authors declare no competing financial interests.

This work was supported by National Institutes of Health Grants T32 DA029974, R01 DA010241, and P50 DA12756, and the Commonwealth of Pennsylvania CURE Addiction Center of Excellence. We thank the research and clinical staff and nurses at the Center for Studies of Addictions, for their expert assistance throughout the study, the technical staff at the University of Pennsylvania Center for Functional Neuroimaging, and Yin Li, for assistance with image processing. We also thank the National Institute on Drug Abuse for providing the study medication.

Correspondence should be addressed to Anna Rose Childress, Department of Psychiatry, Perelman School of Medicine, University of Pennsylvania, 3900 Chestnut Street, Philadelphia, PA 19104. E-mail: childres@mail.med.upenn.edu.

DOI:10.1523/JNEUROSCI.4977-13.2014

Copyright $\odot 2014$ the authors $\quad 0270-6474 / 14 / 345038-06 \$ 15.00 / 0$
}

that follow (See et al., 2001; Crombag et al., 2002). In humans, such cue-induced responses are often associated with selfreported drug desire (Childress et al., 1999; Boileau et al., 2007; Fotros et al., 2013) and are therefore well positioned as prime targets for relapse prevention.

Mesolimbic activation can even occur to drug cues presented entirely outside of awareness. Using fast event-related BOLD fMRI and a backward-masking paradigm, our laboratory demonstrated that subliminally presented drug cues increased neural activity in the VS, AMY, ventral pallidum (VP), and orbitofrontal cortex (OFC) of drug-addicted individuals (Childress et al., 2008; Wetherill et al., 2014). Pharmacological agents that prevent these early responses to drug cues could play an important role in the treatment of addiction-potentially preventing drug cue-induced motivation from developing into a larger and more difficult to manage state. However, the ability of medications to inhibit such early brain responses has not been demonstrated.

The $\mathrm{GABA}_{\mathrm{B}}$ receptor agonist, baclofen, and other GABAmodulating agents attenuate drug- and/or drug cue-induced mesolimbic neural activation (Lhuillier et al., 2007), DA release (Gerasimov et al., 2001; Fadda et al., 2003), and drug-seeking (Roberts et al., 1996; Campbell et al., 1999; Di Ciano and Everitt, 2003) in laboratory animals. Although the findings of clinical studies have been more mixed, baclofen has been found to reduce 
drug desire and/or use in cocaine-, methamphetamine-, opiate-, nicotine-, and alcohol-dependent populations (for review, see Tyacke et al., 2010). In the current study, we examined whether baclofen could reduce the neural response to subliminal cocaine cues in cocaine-dependent individuals. Given its effects on DA neurotransmission in rodents, and on drug desire and use in humans, we hypothesized that baclofen would inhibit activation to subliminal drug cues in mesolimbic brain regions that receive (i.e., VS, VP, AMY, OFC) or provide (i.e., midbrain) DAergic input. To investigate the specificity of baclofen's effects, we also examined whether baclofen altered the mesolimbic response to other cues of motivational significance (e.g., sexual and aversive cues).

\section{Materials and Methods}

\section{Participants}

Participants were 23 treatment-seeking, cocaine-dependent men, between 18 and 55 years of age, who met DSM-IV criteria for cocaine dependence, described smoking as their primary route of cocaine/crack administration, reported using cocaine on at least 8 of the $30 \mathrm{~d}$ before screening, and were available for a 7 - to 10-d inpatient stay (data from 7 participants were included in a prior report, Childress et al., 2008). No participants reported current use of a medication affecting central dopaminergic neurotransmission or a history of psychosis, seizures, or organic brain syndrome unrelated to cocaine use, and no participants were physically dependent on alcohol or sedative hypnotics. Exclusion criteria included clinically significant cardiovascular, hematologic, hepatic, renal, neurological, or endocrine abnormalities; history of head trauma or injury; and contraindications for MRI. Participants were recruited through advertisements in local media and flyers posted throughout the Philadelphia metropolitan area. All participants provided written informed consent and underwent a psychiatric and medical screening before enrollment. This study adhered to the Declaration of Helsinki and was approved by the University of Pennsylvania Institutional Review Board.

\section{Study design}

Following enrollment, participants were admitted to a supervised drugfree residential setting and were randomized to receive baclofen $(60$ $\mathrm{mg} / \mathrm{d} ; 20 \mathrm{mg}$ t.i.d.; $n=11)$ or placebo $(n=12)$ using a double-blind design (Murty Pharmaceuticals). The dose of baclofen was gradually titrated up to $60 \mathrm{mg}$ between treatment days 1 and 6. On treatment days 7-9, while taking the full dose of study medication, participants completed the backward-masking paradigm as the first task in a BOLD fMRI scanning session. Other brain and behavioral measures were subsequently acquired and will be the focus of other reports.

\section{Interviews and questionnaires}

The Mini International Neuropsychiatric Interview was used to determine whether subjects met DSM-IV criteria for cocaine dependence or other Axis 1 psychiatric disorders (Sheehan et al., 1998). Drug and alcohol use history was assessed with the Addiction Severity Index (McLellan et al., 1992). General intelligence (IQ) was estimated using the Wechsler Abbreviated Scale of Intelligence (Wechsler, 1999).

\section{fMRI backward-masked cue task and stimuli}

We used a backward-masking paradigm with a fast event-related fMRI design to measure neural responses to subliminally presented target stimuli, as described in detail previously (Childress et al., 2008). A particular strength of this paradigm is that stimuli can be presented without the potential confounds (e.g., shame, embarrassment, regret) that can occur to consciously presented stimuli. Briefly, this passive viewing task consisted of 192 trials and lasted $\sim 8.5 \mathrm{~min}$. Each trial lasted $2000 \mathrm{~ms}$ and consisted of the display of the following visual stimuli in sequence: 500 ms fixation cross, 33 ms target stimulus, 467 ms masking stimulus; and $1000 \mathrm{~ms}$ fixation cross (Fig. 1). Thus, the stimulus-onset-asynchrony (SOA) between target and mask was $33 \mathrm{~ms}$. This design was chosen because the presentation of a longer masking stimulus immediately after

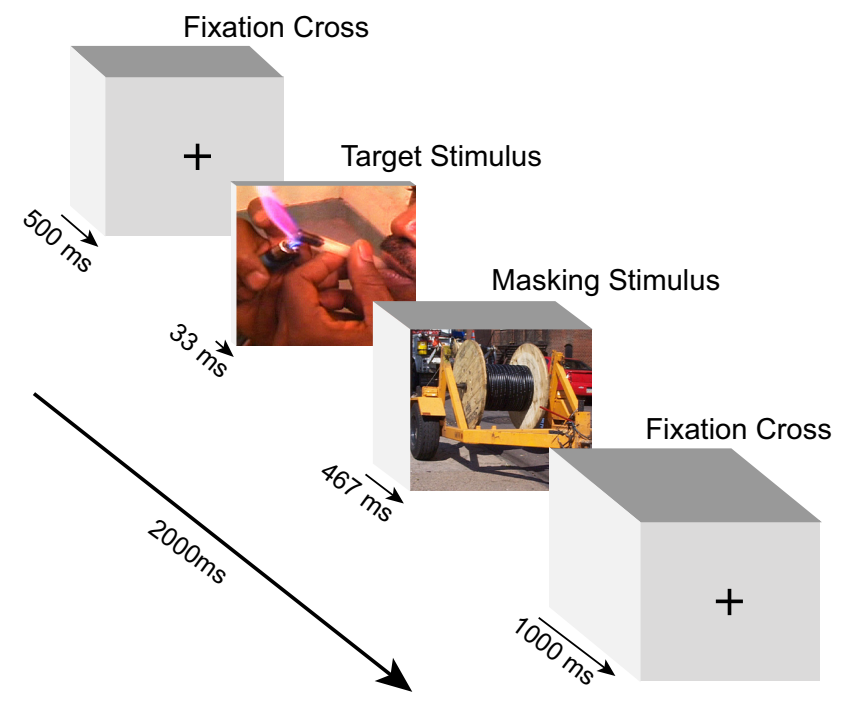

Figure 1. Representative trial from the backward-masked cue task. In each trial, participants were presented with the following visual stimuli in immediate succession: crosshair (500 ms); target stimulus (33 ms); masking stimulus (467 ms); crosshair (1000 ms). Target images were presented from one of four categories [i.e., cocaine (shown), neutral, sexual, and aversive].

a very brief target stimulus (e.g., $20-33 \mathrm{~ms}$ ), with an SOA $<40 \mathrm{~ms}$, has been demonstrated to effectively prevent conscious visual processing of emotional targets (Esteves and Ohman, 1993; Whalen et al., 1998). Importantly, we previously demonstrated, using a forced choice categorization task, that these backward-masking procedures prevent the conscious perception of these same target stimuli in cocaine-dependent men (Childress et al., 2008). Target stimuli consisted of cocaine (use and preparation), sexual (heterosexual erotic scenes), aversive (disfigured/ mutilated bodies), and neutral (outdoor/office objects) images ( $24 \mathrm{im}$ ages per category; for details, see Childress et al., 2008), and were presented quasi-randomly, each without replacement until all stimuli were shown (96 trials). Masking stimuli consisted of 48 additional neutral images and were presented randomly without replacement until all stimuli were shown and were then presented randomly again. This entire process was immediately repeated in a second 96 trial cycle. To optimize the efficiency of the event-related design, 48 null stimuli (i.e., fixation crosses) of $2000 \mathrm{~ms}$ duration were quasirandomly displayed between trials in each cycle, as guided by OptSeq (http://surfer.nmr.mgh.harvard.edu/optseq).

\section{fMRI acquisition}

On the day of the BOLD scan, participants provided a urine sample to verify a cocaine-free state, and adverse events were assessed. Imaging data were acquired using a 3T whole-body scanner (Siemens AG) equipped with a standard 8-channel receive-only array head coil, at the Hospital of the University of Pennsylvania. After participants were positioned in the scanner, a $5 \mathrm{~min}$ high-resolution three-dimensional T1-weighted MPRAGE structural scan [repetition time (TR) 1620 ms; echo time (TE) $3.87 \mathrm{~ms}$; 160 slices; slice thickness $1 \mathrm{~mm}$; matrix $192 \times 256$; flip angle $\left.15^{\circ}\right]$ was acquired, which was used for coregistration and normalization. Functional images were acquired with a T2*-weighted gradient-echo EPI sequence with the following parameters: TR $2000 \mathrm{~ms}$; TE $30 \mathrm{~ms} ; 33$ interleaved slices; slice thickness $3 \mathrm{~mm}$ without any gap between adjacent slices; FOV $192 \mathrm{~mm}$; matrix $64 \times 64$; flip angle $80^{\circ}$.

\section{Data analysis}

Two subjects withdrew from the study before participating in the fMRI session and incomplete fMRI data were acquired on one subject due to technical difficulties. Thus, 20 participants $(n=10$ baclofen; $n=10$ placebo) contributed utilizable fMRI data and were included in analysis. Group differences in age, years of education, estimated IQ, and prior drug use were assessed with independent-samples $t$ tests using SPSS (Version 19). 
Table 1. Participant characteristics

\begin{tabular}{lccc}
\hline & Placebo $(n=10)$ & Baclofen $(n=10)$ & $p$ value \\
\hline Basic demographics & & & \\
Age (years) [mean (SEM)] & $40.20(1.93)$ & $42.00(1.26)$ & 0.45 \\
Education (years) [mean (SEM)] & $12.80(0.35)$ & $12.75(0.86)$ & 0.96 \\
Estimated IQ (WASI) [mean (SEM)] & $98.40(2.01)$ & $92.00(6.19)$ & 0.32 \\
Race (Number) & & & \\
$\quad$ Black & 8 & 10 & \\
$\quad$ Other & 2 & 0 & \\
Prior drug use [mean (SEM)] & & & \\
Cocaine use (years) & $17.10(1.66)$ & $17.20(1.31)$ & 0.96 \\
Cocaine use (days in past 30) & $17.20(3.26)$ & $20.20(2.69)$ & 0.49 \\
Alcohol use (years) & $12.40(3.23)$ & $11.40(3.61)$ & 0.84 \\
Alcohol use (days in past 30) & $6.70(2.99)$ & $8.70(3.75)$ & 0.68 \\
Marijuana use (years) & $10.9(2.45)$ & $7.7(3.28)$ & 0.44 \\
Marijuana use (days in past 30) & $2.1(0.82)$ & $2.9(2.0)$ & 0.73 \\
\hline
\end{tabular}

Image preprocessing. fMRI data were preprocessed using Statistical Parametric Mapping (SPM8; Wellcome Department of Cognitive Neurology, London, UK) in the Matlab (www.mathworks.com) environment. Functional images from each participant were slice-time corrected and realigned to correct for within-volume movement. Significant principle motion components derived from singular vector decomposition were removed and data were then filtered, spatially smoothed using a 9 $\mathrm{mm}^{3}$ full-width half-maximum Gaussian kernel, and normalized to standard Montreal Neurological Institute (MNI) space.

Statistical analysis. All statistical imaging analyses were performed in standard space using SPM8. For each subject, a general linear model using a canonical hemodynamic response basis function with temporal and dispersion derivatives was used to model the regressors of interest, creating three first-level contrasts (cocaine vs neutral, sex vs neutral, and aversive vs neutral). A $2 \times 3$ ANOVA was used to examine the effects of treatment group (baclofen vs placebo) and the three cue conditions (cocaine vs neutral, sex vs neutral, and aversive vs neutral) on neural activation. Three planned second-level $t$ tests were then used to compare the effects of baclofen vs placebo on each cue condition. To control for Type 1 error in these second-level analyses, we selected a multiple-comparison cluster-corrected combined threshold of $p<0.05$, which was determined by Monte-Carlo simulations to correspond to a voxel threshold of $p<$ 0.005 and a cluster size of $>513$ voxels (cocaine vs neutral), $>445$ voxels (sex vs neutral), or $>370$ voxels (aversive vs neutral; $3 \mathrm{dClustSim}$ software; http://afni.nimh.nih.gov/). It is worth noting that our second-level $t$ tests were conducted as unbiased whole-brain analyses; we did not constrain these analyses to voxels that showed a significant interaction effect in the $2 \times 3$ ANOVA. This analytic approach prevents the problem of inflated statistical significance (i.e., "double-dipping") that can occur when a statistically selected subset of data is used in secondary analyses (Kriegeskorte et al., 2009). Regions of activation were identified manually using the Harvard-Oxford probabilistic anatomical atlas within the FMRIB Software Library (FSL). Although all regions of activation are reported, we limit our discussion to effects found in our regions of a priori interest.

\section{Results}

\section{Demographic and clinical results}

Basic demographic and substance use characteristics are presented in Table 1. There were no differences between groups in age, years of education, estimated IQ, race, or prior cocaine, alcohol, or marijuana use. The majority of participants reported no adverse events on BOLD scan day. Of the participants who did, the most common adverse event reported was drowsiness (placebo, $n=2$; baclofen, $n=1$ ). Scan-day urine samples from all participants were negative for recent cocaine use.

\section{Imaging results}

Treatment and cue condition interact to mediate neural activation The $2 \times 3$ ANOVA revealed a significant interaction between treatment group (baclofen vs placebo) and cue condition (cocaine vs neutral, sex vs neutral, and aversive vs neutral) on neural activation $\left(F_{(1.54)}=4.02 ; p<0.05\right)$. This interaction effect was reflected in a large interconnected cluster of voxels that encompassed all our regions of a priori interest (VS, VP, AMY, OFC, and midbrain).

Baclofen blunts the mesolimbic response to subliminal cocaine cues The second-level planned $t$ tests demonstrated that neural activation in response to subliminal cocaine (vs neutral) cues was significantly lower in baclofen-treated than placebotreated participants in each of our a priori mesolimbic regions $\left(t_{(18)}=2.87\right.$; voxel threshold $p<0.005$, cluster corrected at $p<0.05)$. This effect was visualized as an interconnected cluster of 2576 contiguous voxels bilaterally spanning the VS, VP, AMY, OFC, and midbrain (Fig. 2A). Peak voxels for each a priori and non-a priori region within this cluster are reported in Table 2. There were no brain regions in which the response to cocaine cues was greater in baclofen-treated than placebo-treated participants. Additionally, no differences were found between baclofen- and placebo-treated participants in the response to either sexual or aversive (vs neutral) cues in any brain regions at the cluster-corrected threshold used for these $t$ tests, indicating the specificity of baclofen's effects on the neural response to cocaine cues.

Because previous reports have indicated that baclofen might have smaller effects on the response to non-drug, relative to drug, reinforcers (Roberts et al., 1996), we further examined the response to sexual and aversive (vs neutral) cues at two additional, more relaxed, thresholds (i.e., $p<0.005$ and $p<0.01$, each with a minimum extent of 10 contiguous voxels, uncorrected) to examine baclofen's "degree of specificity." The more stringent of these two thresholds was chosen since it provides an acceptable balance between type I and type II error rates in fMRI data (Lieberman and Cunningham, 2009). The less stringent threshold reflects our focus on 5 a priori regions of interest $(p<0.05 / 5$ tests $=p<0.01$ ). At $p<0.005$, baclofen-treated, relative to placebo-treated, participants had lower responses to sexual cues in the midbrain (peak coordinate: $6,-20,-18 ; t=-3.45$ ) and the ventral pallidum (peak coordinate: $-16,-4,-4 ; t=-4.03$ ). At $p<0.01$, responses were additionally reduced in the ventral striatum (peak coordinate: $-12,2,-8 ; t=-2.68$ ) and orbitofrontal cortex (peak coordinate: 40, 20, $-20 ; t=-2.78$ ) of baclofen-treated participants. For aversive cues, at $p<0.005$, there were still no differences in the neural response between baclofen- and placebo-treated groups. However, at the most relaxed threshold of $p<0.01$, baclofen-treated participants had lower responses to aversive cues in the midbrain (peak coordinate: $-4,-16,-16 ; t=-2.82$ ).

Cocaine, sexual, and aversive cues elicit mesolimbic activation As a basic confirmation that our cues elicited activation in our brain regions of interest, we examined the neural response to cocaine, sexual, and aversive cues (vs neutral cues) in the placebo group. For these illustrative single-group analyses, we used the relaxed threshold of $p<0.01, k>10$, uncorrected. Cocaine cues induced activation in the bilateral VS (peak coordinate left: -18 , $6,-14 ; t=4.56$; peak coordinate right: $14,2,-14 ; t=4.65)$, VP (peak coordinate left: $-26,-14,-6 ; t=4.02$; peak coordinate right: $12,0,-6 ; t=4.67$ ), AMY (peak coordinate left: $-18,0$, $-18 ; t=3.18$; peak coordinate right: $16,0,-16 ; t=4.01$ ), OFC 


\section{A}

\section{Baclofen $<$ Placebo}

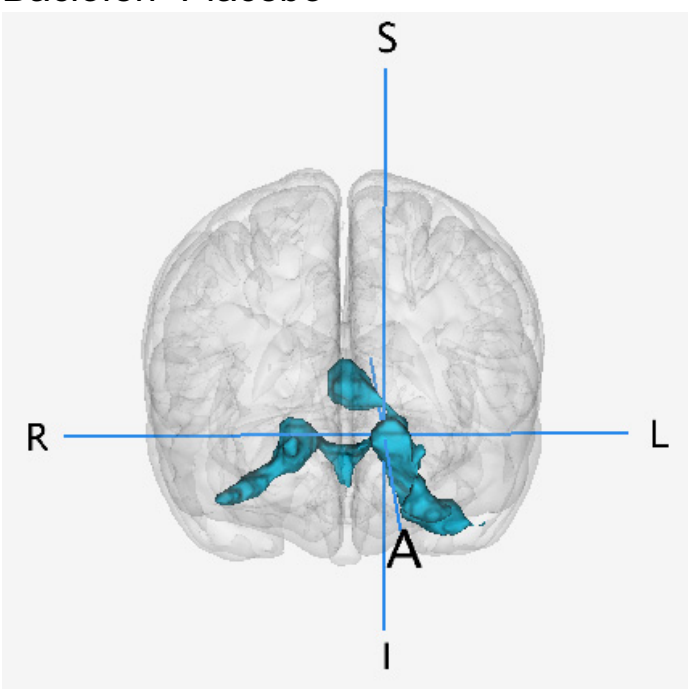

B
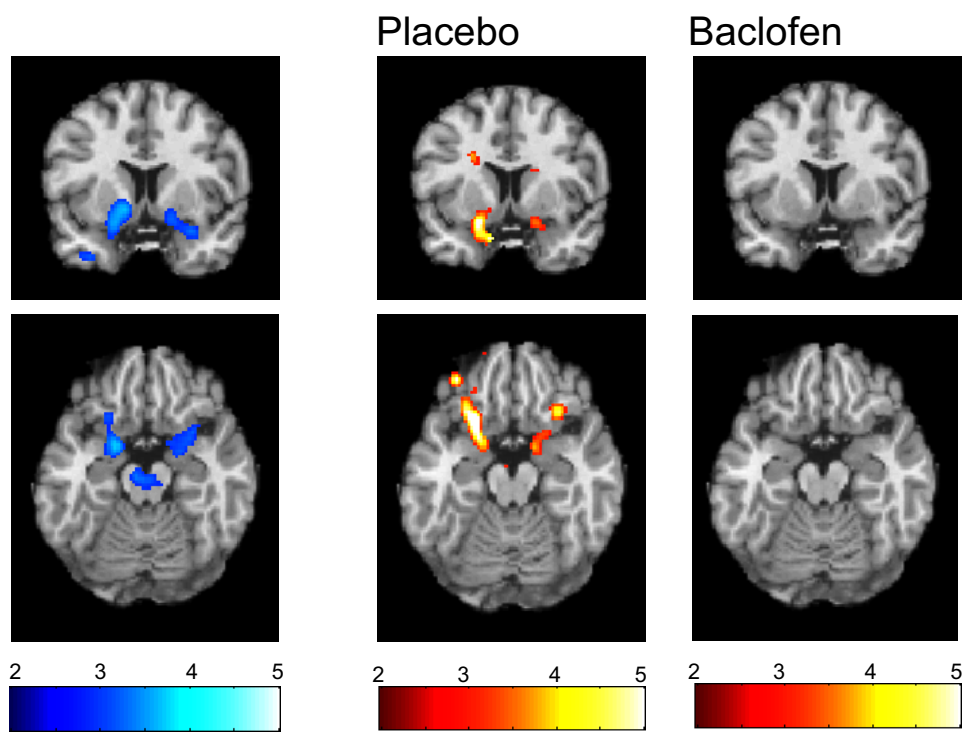

Figure 2. Neural activation to backward-masked cocaine (vs neutral) cues in baclofen- and placebo-treated cocaine-dependent men. $\boldsymbol{A}$, Baclofen-treated compared with placebo-treated participants demonstrated significantly less neural activation in a large interconnected cluster bilaterally spanning the ventral striatum, ventral pallidum, amygdala, midbrain, and orbitofrontal cortex (voxel threshold $p<0.005$; cluster corrected at $p<0.05$ ). The image on the left shows the significant cluster of reduced activation rendered in 3D (crosshairs are centered on the left ventral striatum. S, Superior; I, inferior; A, anterior; R, right; L, left). Cross-sectional coronal and axial images of ventral striatum, amygdala, and midbrain are displayed on the right. $\boldsymbol{B}$, Placebo-treated participants demonstrated increased neural activation in response to cocaine (vs neutral) cues in the ventral striatum, ventral pallidum, amygdala, and orbitofrontal cortex (left); neural activation to cocaine cues was absent in baclofen-treated participants (right; data displayed at $p<0.01, k>10$, uncorrected). For cross-sectional images, data are displayed neurologically (left is left) and the color bars represent $T$ values.

Table 2. Regions of reduced activation in response to subliminal cocaine cues in baclofen-treated compared with placebo-treated participants

\begin{tabular}{|c|c|c|c|c|c|}
\hline \multirow[b]{2}{*}{ Region } & \multirow[b]{2}{*}{ Hemisphere } & \multicolumn{3}{|c|}{ MNI coordinates } & \multirow[b]{2}{*}{$T$-values } \\
\hline & & $x$ & $y$ & $Z$ & \\
\hline \multicolumn{6}{|l|}{ A priori regions } \\
\hline \multirow[t]{2}{*}{ Nucleus accumbens } & $\mathrm{L}$ & -14 & 4 & -8 & -3.86 \\
\hline & $\mathrm{R}$ & 16 & 4 & -10 & -3.57 \\
\hline \multirow[t]{2}{*}{ Ventral pallidum } & $\mathrm{L}$ & -14 & 4 & -6 & -3.83 \\
\hline & $\mathrm{R}$ & 16 & -2 & -8 & -4.19 \\
\hline \multirow[t]{2}{*}{ Amygdala } & $\mathrm{L}$ & -18 & 0 & -20 & -3.48 \\
\hline & $\mathrm{R}$ & 18 & -4 & -12 & -3.55 \\
\hline \multirow[t]{2}{*}{ Orbitofrontal cortex } & $\mathrm{L}$ & -26 & 22 & -26 & -4.20 \\
\hline & $\mathrm{R}$ & 32 & 14 & -20 & -3.36 \\
\hline \multirow[t]{2}{*}{ Midbrain } & $\mathrm{L}$ & -4 & -16 & -18 & -3.32 \\
\hline & $\mathrm{R}$ & 0 & -20 & -20 & -3.29 \\
\hline \multicolumn{6}{|l|}{ Non-a priori regions } \\
\hline Uncus & $\mathrm{L}$ & -30 & 4 & -36 & -4.22 \\
\hline Inferior frontal gyrus & $\mathrm{L}$ & -26 & 22 & -26 & -4.20 \\
\hline \multirow[t]{2}{*}{ Thalamus } & $\mathrm{L}$ & -2 & -8 & 4 & -3.56 \\
\hline & $\mathrm{R}$ & 0 & -12 & 8 & -3.55 \\
\hline Pons & $\mathrm{R}$ & 0 & -18 & -30 & -3.23 \\
\hline Substantia nigra & $\mathrm{R}$ & 12 & -18 & -12 & -3.18 \\
\hline Superior temporal gyrus & $\mathrm{L}$ & -44 & 12 & -34 & -3.00 \\
\hline
\end{tabular}

MNI coordinates and $T$-values of local maxima are shown for each region within the significant cluster (voxel threshold $p<0.005$; cluster-corrected $p<0.05$ ). L, Left; R, right.

(peak coordinate left: $-22,18,-16 ; t=7.74$; peak coordinate right: $32,24,-18 ; t=4.45$ ), and midbrain (peak coordinate: -6 , $-18,-14 ; t=3.08$ ) of placebo (but not baclofen)-treated participants, as expected (Fig. 2B). Sexual and aversive cues also induced mesolimbic activation in placebo-treated participants: activation in the VP (peak coordinate: $-16,-6,-2 ; t=4.32$ ), AMY (peak coordinate: $-20,-6,-10 ; t=2.9$ ) midbrain (peak coordinate: $-8,-20,-12 ; t=3.2$ ), and bilateral OFC (peak coordinate left: $-34,36,-20 ; t=4.05$; peak coordinate right: 40 , $20,-20 ; t=3.09$ ) was noted in response to sexual cues, and activation in the AMY (peak coordinate: $14,-8,-18 ; t=3.89$ ) and midbrain (peak coordinate: $8,-10,-14 ; t=3.62$ ) was noted in response to aversive cues.

\section{Discussion}

The current study tested the hypothesis that baclofen, a $\mathrm{GABA}_{\mathrm{B}}$ receptor agonist, inhibits the neural response to drug cues presented outside of awareness. We demonstrate that participants treated with baclofen display significantly less activation in a large interconnected cluster spanning the VS, VP, AMY, OFC, and midbrain in response to subliminal cocaine cues than those treated with placebo. These results replicate our previous findings that subliminal drug cues elicit mesolimbic activation (Childress et al., 2008; Wetherill et al., 2014) and suggest that baclofen may prevent this effect, providing the first demonstration that the brain response to subliminal drug cues can be pharmacologically inhibited. Further, we demonstrate no significant differences between baclofen- and placebo-treated participants in the neural response to sexual or aversive cues, indicating that the effects of baclofen on cue-induced mesolimbic activation were specific to the drug cues. Given the well accepted role of the mesolimbic reward circuit in drug reward and motivation, our findings indicate that one potential mechanism by which baclofen could have a therapeutic benefit in addiction is by "nipping in the bud" the early motivational processing in response to drug cues-preventing the earliest onset of drug cue-induced motivation before it ever reaches a state of conscious desire.

The effects of baclofen on drug cue-induced limbic activation are consistent with previously published observations in humans. For example, in preliminary work in our laboratory using positron emission tomography (PET) with $\mathrm{O}^{15}-\mathrm{H}_{2} \mathrm{O}$, we examined cocaine cue-induced limbic activation in a small sample of cocaine-dependent men taking baclofen (10-20 mg b.i.d. for 7-10 d; Brebner et al., 2002): these patients did not display the 
characteristic limbic activation to visible cocaine cues noted previously in unmedicated patients (Childress et al., 1999). Our laboratory has also shown that baclofen can even modulate the same circuitry at rest, since acute $(20 \mathrm{mg})$ or long-term $(80 \mathrm{mg} / \mathrm{d} ; 20$ mg q.i.d. for $21 \mathrm{~d}$ ) treatment reduced resting cerebral blood flow in various limbic structures, including the VS, AMY, and/or medial OFC (Franklin et al., 2011, 2012). Together, these results support the hypothesis that baclofen may modulate neural activity in the human brain in regions involved in drug-motivated behavior.

A large body of research has demonstrated that drugs and their conditioned cues elicit DA release in the VS and AMY (Ito et al., 2000; Weiss et al., 2000; Boileau et al., 2007; Fotros et al., 2013). Further, systemic administration of baclofen, and other GABA-modulating agents, attenuates both drug-induced (e.g., cocaine, nicotine, morphine; Fadda et al., 2003) and drug cueinduced (Gerasimov et al., 2001) DA release-presumably by activating $\mathrm{GABA}_{\mathrm{B}}$ receptors located on DA neurons in the ventral tegmental area of the midbrain. Given that baclofen modulates mesolimbic DA release in rodents, it is possible that the effects of baclofen on subliminal cue-induced activation noted here are related to baclofen-induced alterations in DA release. In support of this idea, DA release in response to visible drug cues occurs quite rapidly (i.e., <100 ms; Phillips et al., 2003) and could therefore mediate neural activation in response to subliminal drug cues. Further, medications that directly alter dopaminergic neurotransmission (e.g., haloperidol, levodopa) have recently been found to modulate mesolimbic activation induced by subliminally presented rewarding (e.g., sexual) stimuli (Oei et al., 2012). Although it is therefore likely that baclofen's modulation of mesolimbic DA mediates the effects noted here, further exploration using techniques such as PET will be required to directly examine the neurochemical mechanisms involved.

The relative specificity of baclofen's effects on the neural response to drug-related cues is largely consistent with animal studies documenting baclofen's differential effects on appetitive motivation for drugs versus other rewards (e.g., food, sex). In rodent self-administration paradigms, for example, nonsedating doses of baclofen inhibited responding for cocaine, an index of drug-related motivation, but had less of an effect on responding for food (Roberts et al., 1996). Comparable doses of baclofen also had little to no effect on various indices of sexual motivation (Agmo and Soria, 1997). Similarly, in humans, baclofen has been found to dose-specifically reduce cocaine self-administration (Haney et al., 2006), but to have little to no effect on appetitive motivation for natural rewards (e.g., desire for food/sex; Denys et al., 1998; Jones et al., 2008). Our data provide additional evidence that baclofen, at $60 \mathrm{mg} / \mathrm{d}$, may differentially affect motivational processing for drugs of abuse relative to other types of reinforcers: at the cluster-corrected threshold used for our planned analyses, baclofen reduced mesolimbic responses to cocaine cues, but had no effect on the response to sexual or aversive cues. However, as evidenced by our degree of specificity analyses that applied relaxed thresholds to these data, it is possible that baclofen and other DA modulators could-in other populations or at other doses-exert more generalized effects on motivational processing. This would not be surprising given the evidence that mesolimbic DA plays a role in various appetitive and aversive motivations (Faure et al., 2008).

When evaluating the current findings, there are several considerations that should be taken into account. First, the sample size was small and the population tested was homogeneous (cocaine-dependent males). To determine the generalizability of these initial findings, it will be important to replicate them in a larger sample and in other populations. Second, although we demonstrate that a baclofen dose of $60 \mathrm{mg} / \mathrm{d}$ is sufficient to prevent limbic activation to cues presented outside awareness, it is possible that higher doses may be required for the full clinical benefit of baclofen to be realized (Kahn et al., 2009). Finally, we examined the impact of baclofen versus placebo at a single time point. This design feature was chosen to ensure that we assessed the impact of baclofen on the very first exposure to cocaine cues, while avoiding the unknown and potentially confounding effects of prior, unreinforced exposure (e.g., extinction). This design depends heavily on randomization as a statistical control for potential differences in baseline cue reactivity. Fortunately, as shown in Table 1, there were no significant differences in demographic or drug use variables between the baclofen- and placebo-treated groups, minimizing the possibility that baseline differences influenced the current findings.

The results of this study have intriguing implications for the treatment of addiction. The field of relapse prevention has focused almost exclusively on strategies to counter conscious drug motivation-and relapse rates remain stubbornly high. However, motivational processes and goal pursuit can be generatedand even operate- entirely outside of awareness (Pessiglione et al., 2007; Bargh et al., 2012). Our findings provide the first evidence that a pharmacotherapy can impact unconscious drug motivational processing in humans. These findings highlight a novel mechanism by which pharmacotherapies, alone or in combination with existing psychosocial treatments, can prevent the earliest brain responses to drug cues and thus may provide a critical form of relapse protection for cue-vulnerable individuals.

\section{References}

Agmo A, Soria P (1997) GABAergic drugs and sexual motivation, receptivity and exploratory behaviors in the female rat. Psychopharmacology 129 : 372-381. CrossRef Medline

Bargh JA, Schwader KL, Hailey SE, Dyer RL, Boothby EJ (2012) Automaticity in social-cognitive processes. Trends Cogn Sci 16:593-605. CrossRef Medline

Boileau I, Dagher A, Leyton M, Welfeld K, Booij L, Diksic M, Benkelfat C (2007) Conditioned dopamine release in humans: a positron emission tomography [11C] raclopride study with amphetamine. J Neurosci 27: 3998-4003. CrossRef Medline

Brebner K, Childress AR, Roberts DC (2002) A potential role for GABA(B) agonists in the treatment of psychostimulant addiction. Alcohol Alcohol 37:478-484. CrossRef Medline

Campbell UC, Lac ST, Carroll ME (1999) Effects of baclofen on maintenance and reinstatement of intravenous cocaine self-administration in rats. Psychopharmacology 143:209-214. CrossRef Medline

Chase HW, Eickhoff SB, Laird AR, Hogarth L (2011) The neural basis of drug stimulus processing and craving: an activation likelihood estimation meta-analysis. Biol Psychiatry 70:785-793. CrossRef Medline

Childress AR, Mozley PD, McElgin W, Fitzgerald J, Reivich M, O’Brien CP (1999) Limbic activation during cue-induced cocaine craving. Am J Psychiatry 156:11-18. Medline

Childress AR, Ehrman RN, Wang Z, Li Y, Sciortino N, Hakun J, Jens W, Suh J, Listerud J, Marquez K, Franklin T, Langleben D, Detre J, O’Brien CP (2008) Prelude to passion: limbic activation by "unseen" drug and sexual cues. PLoS One 3:e1506. CrossRef Medline

Crombag HS, Grimm JW, Shaham Y (2002) Effect of dopamine receptor antagonists on renewal of cocaine seeking by reexposure to drugassociated contextual cues. Neuropsychopharmacology 27:1006-1015. CrossRef Medline

Denys P, Mane M, Azouvi P, Chartier-Kastler E, Thiebaut JB, Bussel B (1998) Side effects of chronic intrathecal baclofen on erection and ejaculation in patients with spinal cord lesions. Arch Phys Med Rehabil 79:494-496. CrossRef Medline

Di Ciano P, Everitt BJ (2003) The GABA(B) receptor agonist baclofen atten- 
uates cocaine- and heroin-seeking behavior by rats. Neuropsychopharmacology 28:510-518. CrossRef Medline

Esteves F, Ohman A (1993) Masking the face: recognition of emotional facial expressions as a function of the parameters of backward masking. Scand J Psychol 34:1-18. CrossRef Medline

Fadda P, Scherma M, Fresu A, Collu M, Fratta W (2003) Baclofen antagonizes nicotine-, cocaine-, and morphine-induced dopamine release in the nucleus accumbens of rat. Synapse 50:1-6. CrossRef Medline

Faure A, Reynolds SM, Richard JM, Berridge KC (2008) Mesolimbic dopamine in desire and dread: enabling motivation to be generated by localized glutamate disruptions in nucleus accumbens. J Neurosci 28: 7184-7192. CrossRef Medline

Fotros A, Casey KF, Larcher K, Verhaeghe JA, Cox SM, Gravel P, Reader AJ, Dagher A, Benkelfat C, Leyton M (2013) Cocaine cue-induced dopamine release in amygdala and hippocampus: a high-resolution PET $\left[{ }^{18} \mathrm{~F}\right]$ fallypride study in cocaine dependent participants. Neuropsychopharmacology 38:1780-1788. CrossRef Medline

Franklin TR, Wang Z, Sciortino N, Harper D, Li Y, Hakun J, Kildea S, Kampman K, Ehrman R, Detre JA, O’Brien CP, Childress AR (2011) Modulation of resting brain cerebral blood flow by the GABA B agonist, baclofen: a longitudinal perfusion fMRI study. Drug Alcohol Depend 117:176-183. CrossRef Medline

Franklin TR, Shin J, Jagannathan K, Suh JJ, Detre JA, O’Brien CP, Childress AR (2012) Acute baclofen diminishes resting baseline blood flow to limbic structures: a perfusion fMRI study. Drug Alcohol Depend 125:60-66. CrossRef Medline

Gerasimov MR, Schiffer WK, Gardner EL, Marsteller DA, Lennon IC, Taylor SJ, Brodie JD, Ashby CR Jr, Dewey SL (2001) GABAergic blockade of cocaine-associated cue-induced increases in nucleus accumbens dopamine. Eur J Pharmacol 414:205-209. CrossRef Medline

Haney M, Hart CL, Foltin RW (2006) Effects of baclofen on cocaine selfadministration: opioid- and nonopioid-dependent volunteers. Neuropsychopharmacology 31:1814-1821. CrossRef Medline

Ito R, Dalley JW, Howes SR, Robbins TW, Everitt BJ (2000) Dissociation in conditioned dopamine release in the nucleus accumbens core and shell in response to cocaine cues and during cocaine-seeking behavior in rats. J Neurosci 20:7489-7495. Medline

Jones ML, Leslie DP, Bilsky G, Bowman B (2008) Effects of intrathecal baclofen on perceived sexual functioning in men with spinal cord injury. J Spinal Cord Med 31:97-102. Medline

Kahn R, Biswas K, Childress AR, Shoptaw S, Fudala PJ, Gorgon L, Montoya I, Collins J, McSherry F, Li SH, Chiang N, Alathari H, Watson D, Liberto J, Beresford T, Stock C, Wallace C, Gruber V, Elkashef A (2009) Multicenter trial of baclofen for abstinence initiation in severe cocainedependent individuals. Drug Alcohol Depend 103:59-64. CrossRef Medline

Kriegeskorte N, Simmons WK, Bellgowan PSF, Baker CI (2009) Circular analysis in systems neuroscience: the dangers of double dipping. Nat Neurosci 12:535-540. CrossRef Medline

Kühn S, Gallinat J (2011) Common biology of craving across legal and illegal drugs - a quantitative meta-analysis of cue-reactivity brain response. Eur J Neurosci 33:1318-1326. CrossRef Medline

Lhuillier L, Mombereau C, Cryan JF, Kaupmann K (2007) GABA(B) receptor-positive modulation decreases selective molecular and behavioral effects of cocaine. Neuropsychopharmacology 32:388-398. CrossRef Medline
Lieberman MD, Cunningham WA (2009) Type I and Type II error concerns in fMRI research: re-balancing the scale. Soc Cogn Affect Neurosci 4:423428. CrossRef Medline

McLellan AT, Kushner H, Metzger D, Peters R, Smith I, Grissom G, Pettinati H, Argeriou M (1992) The fifth edition of the Addiction Severity Index. J Subst Abuse Treat 9:199-213. Medline

Oei NY, Rombouts SA, Soeter RP, van Gerven JM, Both S (2012) Dopamine modulates reward system activity during subconscious processing of sexual stimuli. Neuropsychopharmacology 37:1729-1737. CrossRef Medline

Pessiglione M, Schmidt L, Draganski B, Kalisch R, Lau H, Dolan RJ, Frith CD (2007) How the brain translates money into force: a neuroimaging study of subliminal motivation. Science 316:904-906. CrossRef Medline

Phillips PE, Stuber GD, Heien ML, Wightman RM, Carelli RM (2003) Subsecond dopamine release promotes cocaine seeking. Nature 422:614618. CrossRef Medline

Roberts DC, Andrews MM, Vickers GJ (1996) Baclofen attenuates the reinforcing effects of cocaine in rats. Neuropsychopharmacology 15:417-423. CrossRef Medline

See RE, Kruzich PJ, Grimm JW (2001) Dopamine, but not glutamate, receptor blockade in the basolateral amygdala attenuates conditioned reward in a rat model of relapse to cocaine-seeking behavior. Psychopharmacology 154:301-310. CrossRef Medline

Sheehan DV, Lecrubier Y, Sheehan KH, Amorim P, Janavs J, Weiller E, Hergueta T, Baker R, Dunbar GC (1998) The Mini-International Neuropsychiatric Interview (M.I.N.I.): the development and validation of a structured diagnostic psychiatric interview for DSM-IV and ICD-10. J Clin Psychiatry 59 [Suppl 20]:22-33;quiz 34-57.

Tyacke RJ, Lingford-Hughes A, Reed LJ, Nutt DJ (2010) GABAB receptors in addiction and its treatment. Adv Pharmacol 58:373-396. CrossRef Medline

Volkow ND, Wang GJ, Telang F, Fowler JS, Logan J, Childress AR, Jayne M, Ma Y, Wong C (2006) Cocaine cues and dopamine in dorsal striatum: mechanism of craving in cocaine addiction. J Neurosci 26:6583-6588. CrossRef Medline

Wechsler D (1999) Wechsler abbreviated scale of intelligence manual. San Antonio: Harcourt Brace.

Weiss F, Maldonado-Vlaar CS, Parsons LH, Kerr TM, Smith DL, Ben-Shahar O (2000) Control of cocaine-seeking behavior by drug-associated stimuli in rats: effects on recovery of extinguished operant-responding and extracellular dopamine levels in amygdala and nucleus accumbens. Proc Natl Acad Sci U S A 97:4321-4326. CrossRef Medline

Wetherill RR, Childress AR, Jagannathan K, Bender J, Young KA, Suh JJ, O'Brien CP, Franklin TR (2014) Neural responses to subliminally presented cannabis and other emotionally evocative cues in cannabisdependent individuals. Psychopharmacology 231:1397-1407. CrossRef Medline

Whalen PJ, Rauch SL, Etcoff NL, McInerney SC, Lee MB, Jenike MA (1998) Masked presentations of emotional facial expressions modulate amygdala activity without explicit knowledge. J Neurosci 18:411-418. Medline

Wong DF, Kuwabara H, Schretlen DJ, Bonson KR, Zhou Y, Nandi A, Brasic JR, Kimes AS, Maris MA, Kumar A, Contoreggi C, Links J, Ernst M, Rousset O, Zukin S, Grace AA, Lee JS, Rohde C, Jasinski DR, Gjedde A, London ED (2006) Increased occupancy of dopamine receptors in human striatum during cue-elicited cocaine craving. Neuropsychopharmacology 31:2716-2727. Medline 